\title{
Forecasting of Air and Water Temperatures for Fishery Purposes with Selected Examples from Northwest Atlantic
}

\author{
M. Stein \\ Institut für Seefischerei, Palmaille 9 \\ D-22767 Hamburg, Germany \\ and \\ J. Lloret \\ Institut de Ciències del Mar-CSIC, Pg. Joan de Borbó sn \\ E-08039 Barcelona, Catalonia, Spain
}

\begin{abstract}
Statistical methods were used to describe and forecast monthly mean air and bottom water temperatures from 3 sites in the Northwest Atlantic region, up to one year in advance. ARIMA (Auto-Regressive-Integrated-Moving- Average) models were developed that accounted for $92 \%$ of the total variability in the long-term time series of monthly means of air temperature and $80 \%$ for bottom water temperatures. These models were then used to forecast conditions in 1999, with results showing good agreement between the predicted and observed values of both air and bottom water temperatures. Intervention analysis that models events as step-like features was also carried out. While this provided a better model fit to the observed data series, such events can not be predicted. Since nearly all fitted interventions appeared during winter (December-March), prediction of temperatures during these months must be viewed with caution. Results showed that the use of ARIMA models yields better forecasts for highly variable time series than simple models based upon averages of previous monthly averages alone.
\end{abstract}

Keywords: ARIMA, air temperature, Box-Jenkins models, Greenland, intervention analysis, Newfoundland, water temperature

\section{Introduction}

Applied fishery science, which concerns the assessment of fish stocks for fisheries purposes, is increasingly requesting environmental forecasts in many areas of the world's oceans. This is because stock projections are influenced by environmental conditions such as cooling or warming trends, river runoff and prevailing wind fields. Forecasting of these physical parameters can be achieved by solving differential equations under certain boundary conditions. Such techniques are commonly applied in climate modelling, weather forecasting, and ocean modelling. Another approach is to use statistical techniques based upon persistence in the climate variable one wishes to forecast.

In this paper we explore statistical forecasting techniques using linear and stochastic-dynamic models (Box and Jenkins 1976). In particular, we use univariate Auto-Regressive-Integrated-MovingAverage (ARIMA) models to forecast monthly mean air and bottom water temperatures in the Northwest Atlantic region. Intervention techniques that identify and model step-like shifts in the time series are also applied to obtain better hindcasting of the temperature series.

In the following section we list the three climate time series used in our study and present a brief description of the Box and Jenkins (1976) methods. We examine the statistical properties of the temperature time series, develop predictive models and use them to forecast monthly mean values up to 1 year ahead. The model forecast results are then compared to predictions based the monthly averages of the previous three years. The usefulness of our forecasting methods is disuccsed and we point out possible uncertainties in these forecasts.

\section{Materials and Methods}

Monthly mean air temperatures were obtained from Greenland at Egedesminde $\left(68^{\circ} 42.5^{\prime} \mathrm{N}, 51^{\circ} 44.5^{\prime} \mathrm{W}\right.$; 
1991-98), and Nuuk (641' $\left.\mathrm{N}, 51^{\circ} 44.5^{\prime} \mathrm{W} ; 1960-98\right)$. In addition, monthly mean bottom water temperatures at Station 27 (off St. John's, Newfoundland) were made available by the Canadian Department of Fisheries and Oceans in St. John's, Newfoundland for the period 1960-98. Missing data from Station 27 were linearly interpolated from adjacent months.

Models to hindcast the three temperature time series were first developed based upon linear functions of past values of the series and/or previous random shocks (or errors) using the ARIMA and intervention methods described by Box and Jenkins (1976). The models are predicated on the assumption that present values can be predicted from its past history. These linear, stochastic procedures apply to stationary time series (i.e. no systematic change in mean and variance) whose data are normally distributed. First- or secondorder differencing (non-seasonal and/or seasonal) can be applied to obtain a stationary mean. Non-seasonal or standard differencing is obtained by subtracting adjacent values in the time series, in our case adjacent months. Seasonal differencing is subtracting values one year apart, in our case subtracting the monthly means in year $i$ from the same month in year $i+1$, year $i-1$ from year $i$, etc. Further details are provided in Appendix 1. Logarithmic transformation of the raw data is used to produce stationary variance and a normally distributed time series, if required.

Box and Jenkins (1976) formalized the ARIMA modelling framework by defining three steps to be carried out in the analysis: identify the model, estimate the coefficients and verify the model. Identification of the model (i.e. how many terms to be included) is based on the autocorrelation function (ACF) and partial autocorrelation function (PACF) of the differenced, log-transformed time series (Box and Jenkins, 1976). Estimation of the coefficients of the model is carried out by means of the maximum likelihood method. Verification of the model is done through diagnostic checks of the residuals (histogram and normal probability plot of residuals, standardised residuals and ACF and PACF of the residuals). The performance of ARIMA models is often tested through comparison of predictions with observations not used in the fitted model. In our study, ARIMA models were constructed using temperature data up to and including 1998. Data from 1999 were then used to compare with the model forecasts for that year. A detailed description of the non-seasonal and seasonal ARIMA models and the standardised notation used in this paper is developed in Appendix 1. The software package Force 4/R Research System (Prat et al., 1998) developed by the Polytechnical University of Catalonia was used to fit ARIMA univariate and intervention models to the time series of both air and bottom water temperatures.

The accuracy of the ARIMA forecast model was compared to the average of the monthly means over the previous three years by examining the variance accounted for $\left(r^{2}\right)$ by both models.

In addition, we describe the temperature time series in terms of two basic classes of deterministic components: trend and seasonality. Decomposition of time series provides additional information on their structure and dynamics (Chatfield, 1984; Pankratz, 1991). We use the decomposition method "tramoseats" (Gómez and Maravall, 1997), which is included in the software package Force 4/R Research System and that is an extension of the $\mathrm{X}-11$ decomposition method (Makridakis et al., 1983). Computationally, this method analyzes seasonality and trends by multiple moving averages with appropriate lengths of the moving averages for each component.

The intervention analysis mentioned above is a statistical technique that detects and quantifies nonrandom changes of a variable in a time series (Box and Jenkins, 1976; Chatfield, 1984; Pankratz, 1991). Interventions are non-random because they are due to external forcing. As documented recently (Stein, 1998), there is large variability in the air temperatures and ocean temperatures in the Northwest Atlantic region. Owing to the high serial correlation (lack of independence between successive observations), the t-tests for equality of means cannot be used to test for temperature shifts. Therefore, intervention analysis is used to identify the significance, magnitude and form of such temperature shifts (called interventions) in the time series. While the input of an intervention represents a pulse shift in a given month, the output or consequence of that event may be modelled in several ways. Thus, according to the output, two types of interventions are defined, i.e. pulse and step. A pulse intervention represents a temporary event that affects the level of the temperature regime, and can be modelled as abrupt (i.e. a pulse intervention at $t$ $=1$ shifts the level up or down only during period $t=1$ ) or delayed (i.e. a pulse intervention at $t=1$ causes a decreasing or a increasing response during periods $t+1, t+2, t+3 \ldots)$. The first is called an Additive Outlier (denoted AO) and the second a Temporary-Change intervention (denoted TC). Step interventions may be 
thought of as a permanent change in the level of a time series and are also called Level-Shifts (denoted LS). Interventions are identified and modelled by analysing the residuals from the univariate (ARIMA) models. By carrying out the intervention analysis, we not only obtained improved model estimates (parameters) but also were able to better model large events. However, it is important to note that such events cannot be predicted and hence can not be used for forecasting purposes.

\section{Results}

Water and air temperatures display important seasonal (Fig. 1) and inter-annual fluctuations (Fig. 2). The monthly bottom water temperatures at Station 27 show a general negative trend from the 1960s to the 1990 s with quasi-decadal variability including warming in the late 1990s (Fig. 2A). Especially prolonged low bottom-water temperatures were successively recorded during years $1972-75$ and 1984-96. Seasonally, maximum water temperatures occur in January (Fig. 1). In contrast, maximum air temperatures occur in July (Fig. 1). Air temperatures in Nuuk show a progressive decline from 1960 to around 1990 (Fig. 2B). The monthly average air temperatures at Egedesminde show a progressive warming trend through the 1990s (Fig. 2C), similar to Nuuk.

The final ARIMA models we fitted to the monthly mean air and bottom water temperatures are presented in Table 1. It was not necessary to log-transform the data before fitting the models as the raw data were already normally distributed. Due to the strong

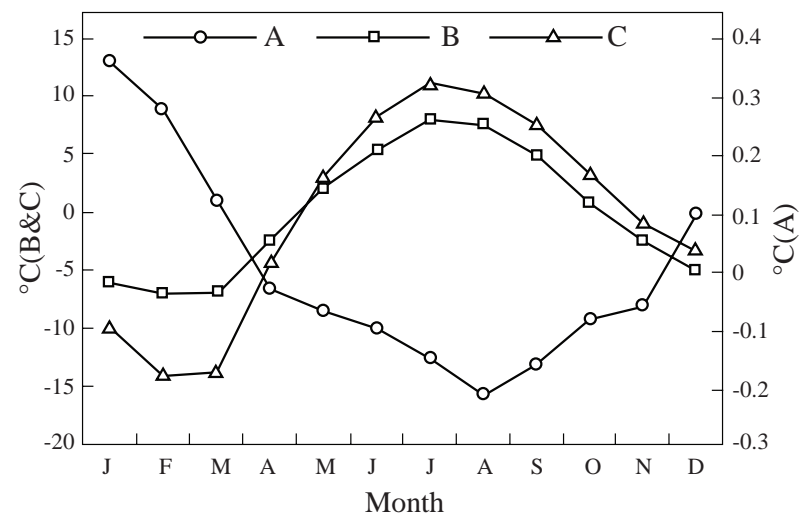

Fig. 1. Mean monthly temperatures (in ${ }^{\circ} \mathrm{C}$ above/below the annual mean): (A) bottom waters at Station 27 (196098), (B) air at Nuuk (1960-98) and (C) air at Egedesminde (1991-98). seasonal cycle, first differencing was required in all cases. Standard differencing was only required in the time series of bottom water temperature at Station 27. Seasonal ARIMA models were fitted to all time series: ARIMA model $(0,1,1) \times 12(0,1,1)$ for the bottom water temperatures at Station 27 and ARIMA models $(1,0,0) \times 12(0,1,1)$ for both Egedesminde and Nuuk air temperatures (see Appendix 1 for details on notation).

The amount of variability accounted for by the models ranged from $80 \%$ for bottom water temperature at Station 27 to $92 \%$ for both time series of air
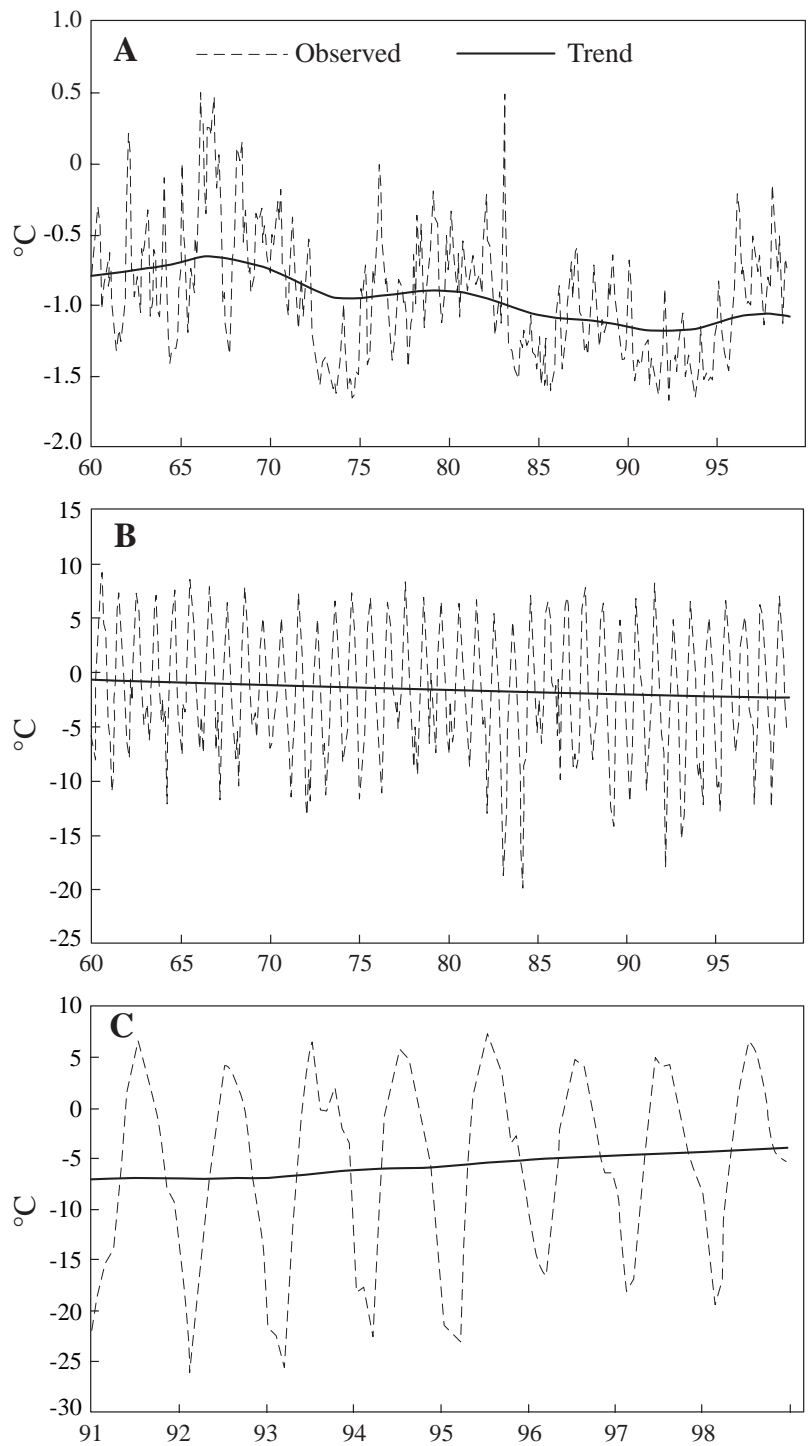

Fig. 2. Observed monthly time series and trend of time series of: (A) bottom water temperature at Station 27, (B) air temperature at Nuuk and $(\mathbf{C})$ air temperature at Egedesminde. 
temperatures (Table 1). Nevertheless, the most important check of any model is to compare predicted values with data not used in establishing the model. Therefore, one-year forecasts of the monthly air and bottom water temperatures were made, and compared with the observed values for 1999 (Fig. 3). The ARIMA model accounted for more variance $\left(r^{2}\right)$ then using the average of the previous 3 years for bottom water temperatures at Station $27(0.39 / 0.80)$. The numbers in brackets refer to the explained variance as given by the average, and the ARIMA model, respectively and air temperatures at Nuuk (0.86/0.92). For air temperatures at Egedesminde both methods yielded about the same accounted for variability $(0.90$ / 0.92).

The intervention analysis revealed 14 significant events $(p<0.05, t>3.0$ or $t<-3.0$; Table 2$)$. Nearly all of these appeared during winter (December-March), e.g. January 1978 and January 1983 Additive Outliers in the bottom water temperatures of Station 27 (Fig. 4). Interventions are the deviations from the predicted values. Thus, each intervention is the difference between the observed and the value expected by the model. For example, the value for the additive outlier (AO) intervention in January 1978 in the time series of water temperatures at Station 27 is $-0.65^{\circ} \mathrm{C}$ (as stated in Table 2). While the expected value for the water temperature in that month (January 1978) was $-0.34^{\circ} \mathrm{C}$, the observed value was $-0.99^{\circ} \mathrm{C}$.

\section{Discussion}

The univariate models for air and bottom water temperatures reveal that it is reasonable to predict their short-term future behaviour based on their past history alone. Models accounted for a large part of the observed variability arising mainly from the seasonal pattern and trend. The structure of the temperature time series was specified for Nuuk and Egedesminde air temperatures as ARIMA models with standard autoregressive term of order 1, and seasonal moving average term of order 1 , and for water temperature at station 27 as ARIMA model with standard and seasonal moving average terms of order 1. The ARIMA model yielded considerable higher precision in forecast for highly variable time series such as the Station 27 bottom water temperatures $\left(r^{2}=0.80\right)$, whereas predictions based on the monthly averages of the previous three years yielded an $r^{2}=0.39$.

The two air-temperature time series show less difference between the ARIMA model predictions and those based upon the monthly averages of the previous 3 years. This indicates that the Box-Jenkins methodology offers the greatest improvement in forecasting ability over simple averages for those time series with high interannual variability.

Intervention models developed in this paper for air temperatures and bottom water temperatures indicate the existence of temperature shifts which mostly occur during winter in the Northwest Atlantic region. The fact that all these large and unexpected temperature events appeared during wintertime indicates predictions for winter months must be viewed with caution since such events cannot be predicted with the present methodology. Incorporation of winter data into the ARIMA models would increase

TABLE 1. Seasonal ARIMA models fitted to the monthly temperatures of Station 27, Nuuk and Egedesminde. Time period used to fit the models, and the resulting models with the $r^{2}$ are shown. (AR is standard autoregressive term, MA and MAS are standard and seasonal moving average terms as given in Appendix 1, respectively).

\begin{tabular}{|c|c|c|c|c|c|c|}
\hline Station & Time period & Fitted Model & $r^{2}$ & AR-1 & MA-1 & MAS-1 \\
\hline $\begin{array}{l}\text { Station } 27 \text { (NFLD) } \\
\text { Bottom Water } \\
\text { Temperature }\end{array}$ & $\begin{array}{l}\text { January } 1960 \\
\text { December } 1998\end{array}$ & $(0,1,1) \times 12(0,1,1)$ & 0.80 & & 0.098 & 0.958 \\
\hline $\begin{array}{l}\text { Nuuk Air } \\
\text { Temperature }\end{array}$ & $\begin{array}{l}\text { January } 1960 \\
\text { December } 1998\end{array}$ & $(1,0,0) \times 12(0,1,1)$ & 0.92 & 0.327 & & 0.958 \\
\hline $\begin{array}{l}\text { Egedesminde Air } \\
\text { Temperature }\end{array}$ & $\begin{array}{l}\text { January } 1991- \\
\text { December } 1998\end{array}$ & $(1,0,0) \times 12(0,1,1)$ & 0.92 & -0.452 & & 0.418 \\
\hline
\end{tabular}



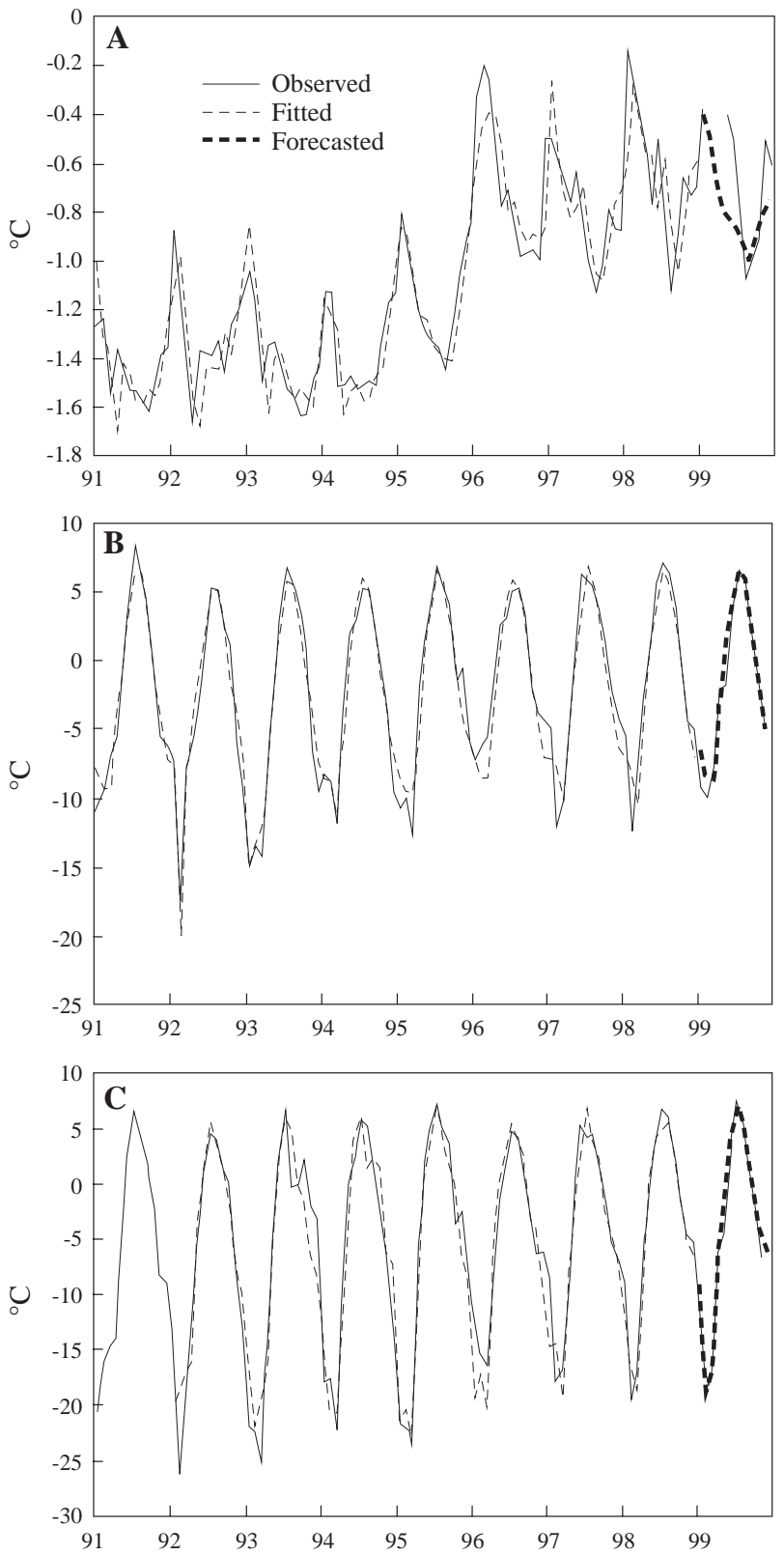

Fig. 3. Comparison of observed monthly temperatures together with fits (for the period January 91December 98 only) and forecasts (for 1999) from models described in Table 1: (A) bottom water temperature at Station 27 (no observations for February and April 1999), (B) air temperature at Nuuk and $(\mathbf{C})$ air temperature at Egedesminde.

the reliability of monthly mean predictions for the remainder of the year.

Although the Box and Jenkins (1976) methodology has been used mainly by the industrial business

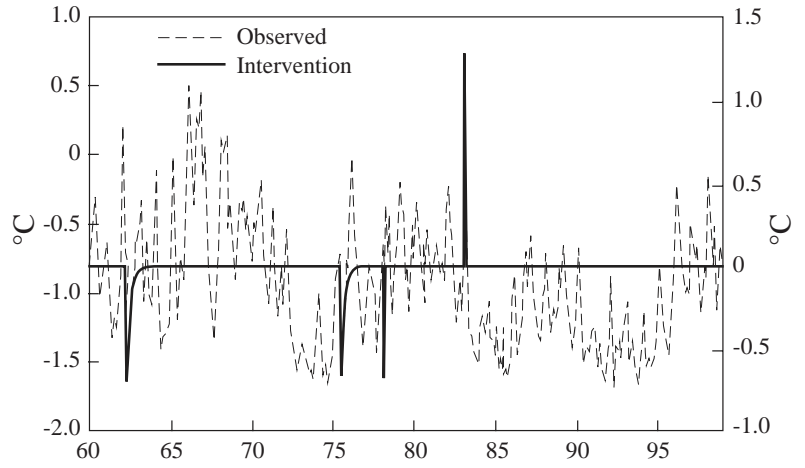

Fig. 4. Temporary Changes (TC) and Additive Outliers (AO) interventions in March 1963, May 1975, January 1978 and January 1983 for the time series of the bottom water temperature in Station 27. The effect of the intervention is shown by a solid line (right axis), while the observed series is plotted with a dashed line (left axis).

managers, economists and engineers, the use of time-series analysis to model fish population dynamics (e.g. Lloret et al., 2000; Stergiou et al., 1997; Quinn and Marshall, 1989) and physical variables (Irvine and Eberhardt, 1992) has increased in recent years. These models are important because they may provide insight into the nature of the system and because of their capability to produce forecasts. In addition, these models avoid some of the statistical problems usually appearing when using pure deterministic and stochastic-static models, i.e. autocorrelation of the observations, co-linearity, residual autocorrelation and non-normal distribution of residuals, which may bias the fit.

\section{Acknowledgements}

The authors thank Ignasi Solé, Albert Prat and J. M. Catot from the Polytechnical University of Catalonia for allowing us to use the time series software package Force 4/Research System. We extend our gratitude to E. B. Colbourne, Department of Fisheries and Oceans, St. John's, Newfoundland, Canada for making available the monthly bottom water temperature data at Station 27. Josep Lloret was financially supported by the D. G. Research of the Government of Catalonia.

\section{References}

BOX, G. E. P., and G. M. JENKINS. 1976. Time Series Analysis: Forecasting and Control. Prentince Hall, Inc. $575 \mathrm{p}$. 
TABLE 2. Interventions incorporated into the ARIMA models: LS (Level-Shifts), AO (Additive Outliers), TC (Temporary-Changes) giving values and significance ( $t$-value) (only significant interventions at $t$-values $>+3$ or $<-3$ are given, showing positive/negative anomalies).

\begin{tabular}{|c|c|c|c|c|c|}
\hline \multirow[b]{2}{*}{ Station } & \multirow[b]{2}{*}{ Date } & \multicolumn{2}{|c|}{$\mathrm{AO}$} & \multicolumn{2}{|c|}{$\mathrm{TC}$} \\
\hline & & Value & $t$ & Value & $t$ \\
\hline \multirow[t]{4}{*}{ Station 27 (NFLD) Bottom } & March 1962 & & & -0.69 & -3.95 \\
\hline & May 1975 & & & -0.65 & -.376 \\
\hline & January 1978 & -0.65 & -4.75 & & \\
\hline & January 1983 & 0.78 & 5.68 & & \\
\hline \multirow[t]{9}{*}{ Nuuk Air Temperature } & March 1962 & 7.14 & 4.43 & & \\
\hline & December 1971 & & & -7.13 & -4.76 \\
\hline & December 1978 & & & 6.28 & 4.21 \\
\hline & January 1983 & & & -9.33 & -6.24 \\
\hline & January 1984 & & & -12.42 & -8.19 \\
\hline & March 1984 & 7.18 & 4.42 & & \\
\hline & February 1986 & 7.62 & 4.75 & & \\
\hline & February 1992 & -9.95 & -5.94 & & \\
\hline & January 1993 & & & -6.92 & -4.59 \\
\hline Egedesminde Air Temperature & Febuary 1992 & -9.90 & -4.52 & & \\
\hline
\end{tabular}

CHATFIELD, C. 1984. The Analysis of Time Series: an Introduction. Chapman \& Hall. 286 p.

GÓMEZ, V., and A. MARAVALL 1997. Tramo-Seats-SCA. Politechnical University of Catalonia. Dept. of Statistics. High School of Engineering. Barcelona.

IRVINE, K. N., and J. EBERHARDT 1992. Multiplicative, seasonal ARIMA models for Lake Erie and Lake Ontario water levels. Water Resources Bulletin, 28(2): 385-396.

LLORET, J., J. LLEONART, and I. SOLÉ 2000. Time series modelling of landings in Northwest Mediterranean Sea. ICES Journal of Marine Science, 57: 171-184.

MAKRIDAKIS, S., S. WHEELWRIGHT, and V. MCGEE. 1983. Forecasting: Methods and Applications. John Wiley \& Sons, Inc. New York. $926 \mathrm{p}$

PANKRATZ, A. 1991. Forecasting with Univariate BoxJenkins Models. John Wiley \& Sons, Inc. 562 p.
PRAT, A., J. M. CATOT, and I. SOLÉ. 1998. Force 4/R Research System. Politechnical University of Catalonia. Dpts. of Statistics. High School of Engineering. Barcelona.

QUINN, T. J., and R. P. MARSHALL 1989. Time series analysis: quantifying variability and correlation in SE Alaska salmon catches and environmental data. Can Spec. Publ. Fish. Aquat. Sci., 108: 67-80.

STERGIOU, K. I., E. D. CHRISTOU, and G. PETRAKIS. 1997. Modelling and forecasting monthly fisheries catches: comparison of regression, univariate and multivariate time series methods. Fisheries Research, 29: 55-95.

STEIN, M. 1998. Integrating fisheries observations with environmental data - towards a better under-standing of the conditions for fish in the sea. J. Northw. Atl. Fish. Sci., 23: 143-156. 


\section{Appendix 1: Standardized ARIMA notation}

ARIMA models have a general form of $(p, d, q)$ where $p$ is the order of the standard autoregressive term (AR), $q$ is order of the standard moving average term (MA) and $d$ is the order of the differencing. AR describes how a variable $Z_{t}$, such as temperature, depends on some previous values $Z_{t-1}$ (AR-1), $Z_{t-2}$ (AR-2), etc. while MA describes how this variable $Z_{t}$ depends on a weighted moving average of the available data $Z_{t-1}$. to $Z_{t-n}$. For example, for a one-step ahead forecast (say, for $t$ being October) with an AR-1, all weight is given to the temperature of the immediately previous month (September), while with an AR-2 the weight is given to the temperature of the 2 immediately previous months (September and August). By contrast, with an MA-1 or MA-2, a certain weight is given to the temperature of the immediately previous month (September), a smaller weight is given to the temperature observed two months ago (August) and so forth, i.e. the weights decline in value exponentially.

The strong seasonally exhibited in most temperature time series renders simple ARIMA modelling inadequate. In these cases, there is a relationship between $Z_{t}$ and $Z_{t-s}$ where $\mathrm{s}$ is the annual cycle, i.e. 12 months. Thus, the multiplicative, seasonal modelling approach which has a general form of ARIMA $(\mathrm{p}, \mathrm{d}, \mathrm{q}) \times$ $s(\mathrm{P}, \mathrm{D}, \mathrm{Q})$ has been used in this paper. In this form, $P$ is order of the seasonal autoregressive term (ARS), $Q$ is the order of the seasonal moving average term (MAS), $D$ is the order of seasonal differencing and $s$ is the annual cycle (e.g. $s=12$ using monthly data). ARS describes how variable $Z$ depends on $Z_{t-12}$ (ARS-1), $Z_{t-24}$ (ARS-2), etc., while MAS describes how $Z$ depends on a weighted moving average of the available data $Z_{t-12}$ to $Z_{t-12 n}$. For example, for a one-step ahead forecast (say, for $t$ being October) and with an ARS-1, all weight is given to the temperature in the previous October while with an ARS-2, the weight is given to October temperatures 1 and 2 years ago. By contrast, with a MAS- 1 or MAS-2, the model gives a certain weight to October temperature 1 year ago, to the October temperature 2 years ago, and so on. These weights decline exponentially. The standardised notation used in this paper to represent ARIMA (p,d,q)x12(P,D,Q) models gives the following model equation,

$$
\phi_{p}(B) \Phi_{P}\left(B^{s}\right) \nabla_{s}^{D} \nabla^{d} Z_{t}=C+\theta_{q}(B) \Theta_{Q}\left(B^{s}\right) a_{t}
$$

This is the standard expression of ARIMA models where $B$ denotes the backward shift operator. By developing the formula according to the indications written here below, we finally get a linear expression of the ARIMA model in the form e.g. $Z_{t}=0.60 Z^{t-1}+0.30 Z^{t-2}+\ldots+0.1 Z^{t-12} \ldots$ and so on. If we have e.g. $B^{2}$, then the linear formula will have a term $Z_{t-2}$, which means dependence of 2 months ago, where:

- $\phi_{p}(B)=1-\phi_{1} B-\phi_{2} B^{2}-\ldots \phi_{\mathrm{p}} B^{p}$ is the standard autoregressive operator of order $p$.

- $\Phi_{P}\left(B^{s}\right)=1-\Phi_{1} B^{s}-\Phi_{2} B^{2 s}{ }_{-\ldots} \Phi_{P} B^{P s}$ is the seasonal autoregressive operator of order $P$.

$-\nabla_{s}^{D}$ is the seasonal differencing operator of order $D$.

$-\nabla^{d}$ is the differencing operator of order $d$.

- $Z_{t}$ is the value of the variable of interest at time $t$.

- $C=\mu \phi_{p}(B) \Phi_{P}\left(B^{s}\right)$ is a constant term, where $\mu$ is the true mean of the stationary time series being modeled. It was estimated from sample data using the approximate likelihood estimator approach.

$-\theta_{q}(B)=1-\theta_{1} B-\theta_{2} B^{2}-\ldots \theta_{q} B^{q}$ is the standard moving average operator of order $q$.

- $\Theta_{Q}\left(B^{s}\right)=1-\Theta_{1} B^{s}-\Theta_{2} B^{2 s}-\ldots \Theta_{Q} \mathrm{~B}^{Q s}$ is the seasonal moving average operator of order $Q$.

- $\phi_{1}, \phi_{2}, \ldots, \phi_{p} ; \Phi_{1}, \Phi_{2}, \ldots, \Phi_{P} ; \theta_{1}, \theta_{2}, \ldots \theta_{q} ; \Theta_{1}, \Theta_{2}, \ldots, \Theta_{Q}$ are unknown coefficients that were estimated from sample data using the approximate likelihood estimator approach.

- $a_{t}$ is the error term at time $t$.

$-s$ is the annual period, i.e. 12 months. 
When modelling, two different options can be used: tramo-seats and SCA options (Gómez and Maravall, 1997). The first one (tramo-seats) is able to construct models in a reasonable time for time series whose structure is relatively easy. This option has been used in our study in all cases. 